\title{
Prediction of Compressive Strength of Concrete Using Artificial Neural Network and Genetic Programming
}

\author{
Palika Chopra, ${ }^{1}$ Rajendra Kumar Sharma, ${ }^{1}$ and Maneek Kumar ${ }^{2}$ \\ ${ }^{1}$ Department of Computer Science and Engineering, Thapar University, Patiala 147004, India \\ ${ }^{2}$ Department of Civil Engineering, Thapar University, Patiala 147004, India \\ Correspondence should be addressed to Palika Chopra; palika.chopra@thapar.edu
}

Received 23 June 2015; Accepted 18 August 2015

Academic Editor: Luigi Nicolais

Copyright (c) 2016 Palika Chopra et al. This is an open access article distributed under the Creative Commons Attribution License, which permits unrestricted use, distribution, and reproduction in any medium, provided the original work is properly cited.

\begin{abstract}
An effort has been made to develop concrete compressive strength prediction models with the help of two emerging data mining techniques, namely, Artificial Neural Networks (ANNs) and Genetic Programming (GP). The data for analysis and model development was collected at 28-, 56-, and 91-day curing periods through experiments conducted in the laboratory under standard controlled conditions. The developed models have also been tested on in situ concrete data taken from literature. A comparison of the prediction results obtained using both the models is presented and it can be inferred that the ANN model with the training function Levenberg-Marquardt (LM) for the prediction of concrete compressive strength is the best prediction tool.
\end{abstract}

\section{Introduction}

Conventional concrete is a mixture of cement, water, and coarse and fine aggregates. Supplementary components such as chemical and mineral admixtures may be added to the basic concrete ingredients to enhance its properties in fresh or hardened state. The procedure of selecting appropriate ingredients for concrete and its relative amount with the aim of producing concrete of obligatory strength, workability, and durability as cost-spinning as possible is termed mix design. The development of tools to find the optimized mix proportions has been the subject of research during the last more than four decades. The aim of any proportioning process is to determine an ample and cost-effective material to make up the concrete, which can be used in its fabrication, as near as possible to the chosen properties. The engineering properties of cement-based materials and special concretes depend on various parameters including the nonhomogeneous nature of their components and the intrinsically different properties of various elements and sometimes on the twin and/or contradictory effects of some ingredients on the overall concrete performance. Therefore, a clear understanding of such complex behavior is needed in order to successfully use these materials in various engineered structures. In recent years, many researchers have been working on developing accurate concrete compressive strength prediction models [1-11]. The prediction of compressive strength of concrete has great connotation, if it is brisk and consistent because it offers an option to do the essential modification on the mix proportion used to avoid circumstances where concrete does not attain the mandatory design strength or by avoiding concrete that is gratuitously sturdy and also for more economic use of raw material and fewer construction failures, hence reducing construction cost. So prediction of compressive strength of concrete has been an active area of research. The aim of the present study is to compare two emerging soft computing techniques, that is, Artificial Neural Network and Genetic Programming (GP), used for concrete compressive strength prediction, by using the experimental data.

\section{Materials}

The experimental data used for the prediction of concrete compressive strength in the present study have been taken from the research work conducted by Kumar [12]. For generating a trustworthy information bank on concrete compressive strength, variation in five parameters, namely, 
water-cementitious material ratio (W/CM), water content, workability, cementitious content (which includes either cement or both cement and fly ash), and curing ages, has been considered. The range for the water-cementitious ratio is between 0.42 and 0.55 , for cement content (C); it is $350-$ 475 at $25 \mathrm{~kg} / \mathrm{m}^{3}$, for water content; it is $180-230$ at $10 \mathrm{~kg} / \mathrm{m}^{3}$, with both medium and high workability, and cured at the ages of 28, 56, and 91 days. The experiments were performed under controlled laboratory conditions. As per IS: 8112-1989, the Ordinary Portland Cement (OPC) is of grade 43 having specific gravity of 3.12 . The specific gravity of the aggregate (sand) is 2.54 with a fineness modulus of 2.09. The sand conforms to zone III as per IS: 383-1970. Coarse aggregate (CA), used herein, consists of two sizes, $20 \mathrm{~mm}$ and $10 \mathrm{~mm}$, having specific gravity of 2.61 and 2.63 , respectively, mixed in varying proportion. The details of the proportions for concrete mixes without fly ash (FA) are shown in Table 1 and the compressive strength data at varying curing ages for these mixes is presented in Table 2. Table 3 shows proportions of ingredients of mixes containing $0.15 \mathrm{FA}$ as substitution of cement and Table 4 gives the compressive strength data at the above ages for the FA concrete mixes.

\section{Methods}

3.1. Artificial Neural Network. An Artificial Neural Network is a network of artificial neurons, which can reveal intricate global performance, determined by the associations between the processing elements and element parameters. In a neural network model, simple nodes, which are called "neurons" or "neurodes" or "processing elements" (PEs) or "units," are linked jointly to form a network of units, hence called "Artificial Neural Network."

ANNs consist of the following three major essentials [13]:

Topology: organization and interconnection of a neural network into layers.

Learning: related with the information storage in the network.

Recall: retrieval of information from the network.

The architecture of an ANN consists of synthetic or artificial neurons. These are analogous to natural neurons in the brain of a human, which are clumped into layers. Atypical neural network architecture consists of an input layer, one hidden layer, and an output layer [14].

3.1.1. Construction of Model 1 (ANN Model). A successful application of an ANN for the prediction of compressive strength of concrete needs a good conception of the impact of different internal parameters. For ANN architectures and training of the same, the significant internal parameters include learning rate, initial weights, number of training epochs, number of hidden layers, and number of neurons in every hidden layer and transfer functions for hidden layers and output layers [15]. In this work, an ANN model is developed through experimental exploration of various internal parameters to predict the compressive strength of concrete. The initial trialing is commenced with certain randomly
TABLE 1: Details of proportions for concrete mixes without fly ash.

\begin{tabular}{|c|c|c|c|c|}
\hline S. number & $\begin{array}{c}\text { Mix } \\
\text { designation }\end{array}$ & $\begin{array}{l}\text { W/CM } \\
\text { ratio }\end{array}$ & $\begin{array}{l}\text { Mix proportions } \\
\text { (C: sand : CA })\end{array}$ & $\begin{array}{c}\text { Cement } \\
\text { content }(\mathrm{C}) \\
\mathrm{kg} / \mathrm{m}^{3}\end{array}$ \\
\hline 1 & MD-1 & 0.53 & $1: 1.58: 3.05$ & 375.00 \\
\hline 2 & MD-2 & 0.50 & $1: 1.43: 2.82$ & 400.00 \\
\hline 3 & MD-3 & 0.53 & $1: 1.54: 2.99$ & 400.00 \\
\hline 4 & MD-4 & 0.47 & $1: 1.28: 2.58$ & 425.00 \\
\hline 5 & MD-5 & 0.49 & $1: 1.39: 2.77$ & 425.00 \\
\hline 6 & MD-6 & 0.44 & $1: 1.14: 2.35$ & 450.00 \\
\hline 7 & MD-7 & 0.47 & $1: 1.25: 2.54$ & 450.00 \\
\hline 8 & MD-8 & 0.42 & $1: 1.05: 2.19$ & 475.00 \\
\hline 9 & MD-9 & 0.44 & $1: 1.19: 2.46$ & 475.00 \\
\hline 10 & MD-10 & 0.53 & $1: 1.58: 3.05$ & 375.00 \\
\hline 11 & MD-11 & 0.50 & $1: 1.43: 2.82$ & 400.00 \\
\hline 12 & MD-12 & 0.53 & $1: 1.54: 2.99$ & 400.00 \\
\hline 13 & MD-13 & 0.47 & $1: 1.28: 2.58$ & 425.00 \\
\hline 14 & MD-14 & 0.49 & $1: 1.39: 2.77$ & 425.00 \\
\hline 15 & MD-15 & 0.51 & $1: 1.51: 2.95$ & 425.00 \\
\hline 16 & MD-16 & 0.44 & $1: 1.14: 2.35$ & 450.00 \\
\hline 17 & MD-17 & 0.47 & $1: 1.25: 2.54$ & 450.00 \\
\hline 18 & MD-18 & 0.49 & $1: 1.37: 2.73$ & 450.00 \\
\hline 19 & MD-19 & 0.42 & $1: 1.05: 2.19$ & 475.00 \\
\hline 20 & MD-20 & 0.44 & $1: 1.19: 2.46$ & 475.00 \\
\hline 21 & MD-21 & 0.46 & $1: 1.23: 2.51$ & 475.00 \\
\hline 22 & MD-22 & 0.52 & $1: 1.43: 2.02$ & 425.00 \\
\hline 23 & MD-23 & 0.49 & $1: 1.29: 1.86$ & 450.00 \\
\hline 24 & MD-24 & 0.51 & $1: 0.391: 1.9$ & 450.00 \\
\hline 25 & MD-25 & 0.46 & $1: 1.17: 1.72$ & 475.00 \\
\hline 26 & MD-26 & 0.48 & $1: 1.26: 1.83$ & 475.00 \\
\hline 27 & MD-27 & 0.51 & $1: 1.39: 3.26$ & 350.00 \\
\hline 28 & MD-28 & 0.54 & $1: 1.49: 3.42$ & 350.00 \\
\hline 29 & MD-29 & 0.48 & $1: 1.25: 2.99$ & 375.00 \\
\hline 30 & MD-30 & 0.51 & $1: 1.35: 3.19$ & 375.00 \\
\hline 31 & MD-31 & 0.45 & $1: 1.10: 2.70$ & 400.00 \\
\hline 32 & MD-32 & 0.48 & $1: 1.21: 2.92$ & 400.00 \\
\hline 33 & MD-33 & 0.42 & $1: 0.98: 2.47$ & 425.00 \\
\hline 34 & MD-34 & 0.45 & $1: 1.09: 2.68$ & 425.00 \\
\hline 35 & MD-35 & 0.42 & $1: 0.98: 2.45$ & 450.00 \\
\hline 36 & MD-36 & 0.54 & $1: 1.49: 3.42$ & 350.00 \\
\hline 37 & MD-37 & 0.51 & $1: 1.35: 3.19$ & 375.00 \\
\hline 38 & MD-38 & 0.48 & $1: 1.21: 2.92$ & 400.00 \\
\hline 39 & MD-39 & 0.45 & $1: 1.09: 2.68$ & 425.00 \\
\hline 40 & $\mathrm{MD}-40$ & 0.42 & $1: 0.98: 2.45$ & 450.00 \\
\hline 41 & MD-41 & 0.53 & $1: 1.47: 2.41$ & 375.00 \\
\hline 42 & MD-42 & 0.50 & $1: 1.32: 2.21$ & 400.00 \\
\hline 43 & MD-43 & 0.53 & $1: 1.44: 2.36$ & 400.00 \\
\hline 44 & $\mathrm{MD}-44$ & 0.47 & $1: 1.19: 2.03$ & 425.00 \\
\hline 45 & MD-45 & 0.49 & $1: 1.29: 2.18$ & 425.00 \\
\hline 46 & $\mathrm{MD}-46$ & 0.44 & $1: 1.07: 1.86$ & 450.00 \\
\hline 47 & MD-47 & 0.47 & $1: 1.17: 2.00$ & 450.00 \\
\hline 48 & MD-48 & 0.42 & $1: 0.95: 1.68$ & 475.00 \\
\hline 49 & MD-49 & 0.44 & $1: 1.06: 1.84$ & 475.00 \\
\hline
\end{tabular}

selected parameters on the basis of the technical literature available. The "trial and error" method is used to reach at best possible parameter values that would generate the true predictions.

In the starting, most of the variants are examined for the network performance optimization. Levenberg-Marquardt 
TABLE 2: Details of compressive strength of concrete mixes without fly ash after curing for 28,56 , and 91 days.

\begin{tabular}{|c|c|c|c|c|c|}
\hline S. number & $\begin{array}{c}\text { Mix } \\
\text { designation }\end{array}$ & $\begin{array}{l}\mathrm{W} / \mathrm{CM} \\
\text { ratio }\end{array}$ & $\begin{array}{c}28 \mathrm{~d} \\
(\mathrm{MPa})\end{array}$ & $\begin{array}{c}56 \mathrm{~d} \\
(\mathrm{MPa})\end{array}$ & $\begin{array}{c}91 \mathrm{~d} \\
(\mathrm{MPa})\end{array}$ \\
\hline 1 & MD-1 & 0.53 & 36.84 & 40.92 & 44.52 \\
\hline 2 & MD-2 & 0.50 & 43.13 & 50.22 & 51.97 \\
\hline 3 & MD-3 & 0.53 & 38.58 & 45.51 & 47.49 \\
\hline 4 & MD-4 & 0.47 & 47.16 & 51.25 & 54.27 \\
\hline 5 & MD-5 & 0.49 & 45.05 & 50.72 & 52.85 \\
\hline 6 & MD-6 & 0.44 & 49.63 & 54.48 & 58.04 \\
\hline 7 & MD-7 & 0.47 & 47.42 & 51.34 & 55.30 \\
\hline 8 & MD-8 & 0.42 & 54.01 & 57.91 & 60.15 \\
\hline 9 & MD-9 & 0.44 & 50.05 & 55.72 & 58.31 \\
\hline 10 & MD-10 & 0.53 & 37.81 & 43.50 & 47.55 \\
\hline 11 & MD-11 & 0.50 & 44.11 & 50.98 & 52.56 \\
\hline 12 & MD-12 & 0.53 & 40.90 & 46.56 & 51.07 \\
\hline 13 & MD-13 & 0.47 & 47.51 & 52.92 & 54.47 \\
\hline 14 & MD-14 & 0.49 & 45.30 & 51.47 & 53.09 \\
\hline 15 & MD-15 & 0.51 & 42.54 & 49.05 & 51.19 \\
\hline 16 & MD-16 & 0.44 & 52.03 & 56.26 & 59.19 \\
\hline 17 & MD-17 & 0.47 & 48.74 & 53.42 & 55.03 \\
\hline 18 & MD-18 & 0.49 & 46.59 & 53.21 & 53.67 \\
\hline 19 & MD-19 & 0.42 & 54.49 & 58.65 & 63.07 \\
\hline 20 & MD-20 & 0.44 & 53.06 & 56.67 & 62.57 \\
\hline 21 & MD-21 & 0.46 & 49.18 & 54.04 & 57.10 \\
\hline 22 & MD-22 & 0.52 & 40.02 & 46.92 & 48.48 \\
\hline 23 & MD-23 & 0.49 & 45.25 & 50.43 & 53.09 \\
\hline 24 & MD-24 & 0.51 & 42.68 & 48.54 & 49.63 \\
\hline 25 & MD-25 & 0.46 & 48.67 & 53.48 & 56.50 \\
\hline 26 & MD-26 & 0.48 & 45.52 & 50.97 & 53.63 \\
\hline 27 & MD-27 & 0.51 & 39.52 & 43.31 & 46.13 \\
\hline 28 & MD-28 & 0.54 & 31.66 & 37.18 & 43.92 \\
\hline 29 & MD-29 & 0.48 & 42.73 & 48.23 & 52.23 \\
\hline 30 & MD-30 & 0.51 & 40.69 & 44.46 & 46.42 \\
\hline 31 & MD-31 & 0.45 & 47.99 & 52.95 & 55.51 \\
\hline 32 & MD-32 & 0.48 & 44.89 & 51.20 & 53.85 \\
\hline 33 & MD-33 & 0.42 & 51.25 & 57.55 & 59.50 \\
\hline 34 & MD-34 & 0.45 & 49.05 & 54.14 & 57.35 \\
\hline 35 & MD-35 & 0.42 & 53.69 & 57.77 & 59.89 \\
\hline 36 & MD-36 & 0.54 & 36.64 & 43.46 & 46.55 \\
\hline 37 & MD-37 & 0.51 & 41.57 & 46.81 & 50.04 \\
\hline 38 & MD-38 & 0.48 & 46.22 & 52.58 & 53.07 \\
\hline 39 & MD-39 & 0.45 & 50.35 & 56.02 & 58.32 \\
\hline 40 & $\mathrm{MD}-40$ & 0.42 & 54.11 & 58.52 & 62.28 \\
\hline 41 & MD-41 & 0.53 & 37.30 & 43.51 & 46.63 \\
\hline 42 & MD-42 & 0.50 & 44.04 & 50.53 & 52.55 \\
\hline 43 & MD-43 & 0.53 & 39.61 & 46.09 & 48.17 \\
\hline 44 & MD-44 & 0.47 & 47.37 & 51.31 & 54.77 \\
\hline 45 & MD-45 & 0.49 & 44.69 & 50.69 & 52.75 \\
\hline 46 & MD-46 & 0.44 & 50.93 & 55.71 & 59.05 \\
\hline 47 & MD-47 & 0.47 & 48.08 & 52.63 & 55.61 \\
\hline 48 & MD-48 & 0.42 & 54.14 & 58.21 & 61.11 \\
\hline 49 & MD-49 & 0.44 & 51.31 & 56.37 & 59.51 \\
\hline
\end{tabular}

training (LM) was found to be most suitable for the data patterns for the prediction of concrete compressive strength during trail approach. In the present study, two types of datasets have been taken: dataset 1 has 49 tuples and this dataset is without the substitution of cement with FA and dataset 2 has 27 tuples and this dataset is with 0.15 substitution of cement with FA. Further each dataset is categorized according to the curing time, that is, 28 days, 56 days, and 91 days. The four numbers of input parameters have been engaged, that is, water, cement, coarse aggregate, and fine aggregate, when the output parameter is 28-day compressive strength. The five numbers of input parameters have been taken including the 28-day compressive strength as input parameter, that is, water, cement, coarse aggregate, fine aggregate, and 28-day compressive strength, when the output parameter is 56-day compressive strength. The six numbers of input parameters have been used including the 28-day compressive strength and 56-day compressive strength as input parameters, that is, water, cement, coarse aggregate, fine aggregate, 28-day compressive strength, and 56-day compressive strength, when the output parameter is 91-day compressive strength. For all the experiments in model $1, \operatorname{tansig}(x)$ function is selected for the hidden layer and purelin $(x)$ function is selected for output layer due to their ability to learn complex nonlinear relation between the input parameter and output parameter [16]. 50 numbers of neurons are used at hidden layer and 01 neuron is used at output layer. The values of other parameters, that is, performance function, learning rate, performance goal, and epochs, are "mse," "0.01," "0.000001," and "10000" which have been taken for the construction of ANN model. The architecture selected for ANN model is given in Table 5 .

3.2. Genetic Programming. Genetic Programming (GP) is a group of instructions and a fitness process to determine how well a machine has performed a particular task. It is a specialization of genetic algorithm (GA) where each node is a computer program. It is a technique used to optimize residents of computer program in line with a suitable site determined by a program's capability to carry out a prearranged computational condition. The three genetic operations are as follows:

(1) Crossover operates on two programs that are chosen as per their fitness and produces two subprograms. The two random nodes are chosen from each program and then the resultant subtrees are swapped, producing two new programs. These new programs turned into a part of the new generation of programs to be participated further. Population here is increased by 2.

(2) Reproduction: the next important operation is accomplished by copying an elected member from the present generation to the subsequent generation as per the fitness norm. Population here is increased by 1.

(3) Mutation: in GP, mutation becomes a significant operator that provides assortment to the population. One individual is chosen as per the fitness. A subprogram is substituted by another one randomly. The mutant is popped into the new population. Population is then increased by 1 .

Saridemir [10] has explained the whole genetic approach proposed by Koza [17] and Ghodratnamaa et al. [18] have also published the pseudocode for the same. The role of GP in future computing has been seen as the most potential way to 
TABLE 3: Details of proportions for concrete mixes with 0.15 fly ash replacement.

\begin{tabular}{|c|c|c|c|c|c|}
\hline S. number & Mix designation & $\mathrm{W} / \mathrm{CM}$ ratio & $\begin{array}{c}\text { Mix proportions } \\
(\mathrm{C}: \mathrm{FA}: \text { sand : } \mathrm{CA})\end{array}$ & $\begin{array}{c}\text { Cement content }(\mathrm{C}) \\
\mathrm{kg} / \mathrm{m}^{3} \\
\end{array}$ & $\begin{array}{c}\text { Fly ash content (FA) } \\
\mathrm{kg} / \mathrm{m}^{3}\end{array}$ \\
\hline 1 & MDF-1 & 0.45 & $1: 0.15: 1.10: 2.70$ & 400.00 & 60.00 \\
\hline 2 & MDF-2 & 0.42 & $1: 0.15: 0.98: 2.46$ & 425.00 & 63.75 \\
\hline 3 & MDF-3 & 0.45 & $1: 0.15: 1.09: 2.68$ & 425.00 & 63.75 \\
\hline 4 & MDF-4 & 0.47 & $1: 0.15: 1.28: 2.58$ & 425.00 & 63.75 \\
\hline 5 & MDF-5 & 0.42 & $1: 0.15: 0.98: 2.45$ & 450.00 & 67.50 \\
\hline 6 & MDF-6 & 0.44 & $1: 0.15: 1.14: 2.35$ & 450.00 & 67.50 \\
\hline 7 & MDF-7 & 0.47 & $1: 0.15: 1.25: 2.54$ & 450.00 & 67.50 \\
\hline 8 & MDF-8 & 0.42 & $1: 0.15: 1.05: 2.19$ & 475.00 & 71.25 \\
\hline 9 & MDF-9 & 0.44 & $1: 0.15: 1.19: 2.46$ & 475.00 & 71.25 \\
\hline 10 & MDF-10 & 0.45 & $1: 0.15: 1.09: 2.68$ & 425.00 & 63.75 \\
\hline 11 & MDF-11 & 0.47 & $1: 0.15: 1.28: 2.58$ & 425.00 & 63.75 \\
\hline 12 & MDF-12 & 0.42 & $1: 0.15: 0.98: 2.45$ & 450.00 & 67.50 \\
\hline 13 & MDF-13 & 0.44 & $1: 0.15: 1.14: 2.35$ & 450.00 & 67.50 \\
\hline 14 & MDF-14 & 0.47 & $1: 0.15: 1.25: 2.54$ & 450.00 & 67.50 \\
\hline 15 & MDF-15 & 0.49 & $1: 0.15: 1.37: 2.73$ & 450.00 & 67.50 \\
\hline 16 & MDF-16 & 0.42 & $1: 0.15: 1.05: 2.19$ & 475.00 & 71.25 \\
\hline 17 & MDF-17 & 0.44 & $1: 0.15: 1.19: 2.46$ & 475.00 & 71.25 \\
\hline 18 & MDF-18 & 0.46 & $1: 0.15: 1.23: 2.51$ & 475.00 & 71.25 \\
\hline 19 & MDF-19 & 0.47 & $1: 0.15: 1.19: 2.03$ & 425.00 & 63.75 \\
\hline 20 & MDF-20 & 0.44 & $1: 0.15: 1.07: 1.86$ & 450.00 & 67.50 \\
\hline 21 & MDF-21 & 0.47 & $1: 0.15: 1.17: 2.00$ & 450.00 & 67.50 \\
\hline 22 & MDF-22 & 0.49 & $1: 0.15: 1.29: 1.86$ & 450.00 & 67.50 \\
\hline 23 & MDF-23 & 0.51 & $1: 0.15: 1.39: 1.98$ & 450.00 & 67.50 \\
\hline 24 & MDF-24 & 0.42 & $1: 0.15: 0.95: 1.68$ & 475.00 & 71.25 \\
\hline 25 & MDF-25 & 0.44 & $1: 0.15: 1.06: 1.84$ & 475.00 & 71.25 \\
\hline 26 & MDF-26 & 0.46 & $1: 0.15: 1.17: 1.72$ & 475.00 & 71.25 \\
\hline 27 & MDF-27 & 0.48 & $1: 0.15: 1.26: 1.83$ & 475.00 & 71.25 \\
\hline
\end{tabular}

automatically write computer programs. Nowadays, some commercial Genetic Programming kernels are also available that will help to apply the technique and to use the GP kernels the user needs to take some decisions before the GP system to begin. Firstly, the available genes need to be selected and created. Secondly, the user has to specify a number of control parameters.

3.2.1. Construction of Model 2 (GP Model). Koza [17] has listed some of the important control parameters. For the construction of GP, the initial population size is 49 for dataset 1 without substitution of cement with FA and 27 with 0.15 substitution of cement with FA for dataset 2 . As in model 1, each dataset is further categorized according to the curing time; the same has been taken for model 2. The four numbers of input parameters have been taken, that is, water, cement, coarse aggregate, and fine aggregate, when the output parameter is 28-day compressive strength.

The five numbers of input parameters have been engaged including the 28-day compressive strength as input parameter, that is, water, cement, coarse aggregate, fine aggregate, and 28-day compressive strength, when the output parameter is 56-day compressive strength. The six numbers of input parameters have been used including the 28-day compressive strength and 56-day compressive strength as input parameters, that is, water, cement, fine aggregate, coarse aggregate, 28-day compressive strength, and 56-day compressive strength, when the output parameter is 91-day compressive strength. The population size $(\mathrm{Mu})$ and the number of children produced (Lamda) have been taken 100 and 150, respectively. The greater the number of generations, the greater the chance of evolving a solution, so the number of generations is taken as 100000 for this model. The values for the parameters crossover rate and mutation rate have been selected as 0.70 and 5.e - 002, respectively, on the trial and error basis. The values of other parameters, that is, function set, training percentage, selection method, and tournament size of substitution, are “+, -, *, /, sqrt," "75," "tournament," and "03" which have been selected for the construction of GP model. The parameters settings for model 2 are lodged in Table 6 .

3.3. Testing of Model 1 and Model 2. Namyong et al. [19] have offered the regression equations for prediction of in situ concrete compressive strength and for this purpose they have 
TABLE 4: Details of compressive strength of concrete mixes with fly ash after curing of 28,56 , and 91 days.

\begin{tabular}{|c|c|c|c|c|c|}
\hline S. number & Mix designation & $\begin{array}{c}\mathrm{W} / \mathrm{CM} \\
\text { ratio }\end{array}$ & $\begin{array}{c}28 \mathrm{~d} \\
(\mathrm{MPa})\end{array}$ & $\begin{array}{c}56 \mathrm{~d} \\
(\mathrm{MPa})\end{array}$ & $\begin{array}{c}91 \mathrm{~d} \\
(\mathrm{MPa})\end{array}$ \\
\hline 1 & MDF-1 & 0.45 & 39.04 & 47.65 & 52.20 \\
\hline 2 & MDF-2 & 0.42 & 45.09 & 50.21 & 55.75 \\
\hline 3 & MDF-3 & 0.45 & 41.14 & 48.67 & 52.69 \\
\hline 4 & $\mathrm{MDF}-4$ & 0.47 & 38.35 & 43.27 & 50.42 \\
\hline 5 & MDF-5 & 0.42 & 46.13 & 51.01 & 56.51 \\
\hline 6 & MDF-6 & 0.44 & 42.50 & 49.17 & 53.11 \\
\hline 7 & MDF-7 & 0.47 & 39.58 & 44.02 & 51.07 \\
\hline 8 & MDF-8 & 0.42 & 47.34 & 52.30 & 57.70 \\
\hline 9 & MDF-9 & 0.44 & 43.55 & 49.79 & 53.79 \\
\hline 10 & MDF-10 & 0.45 & 42.01 & 49.68 & 53.39 \\
\hline 11 & MDF-11 & 0.47 & 38.85 & 44.96 & 50.50 \\
\hline 12 & MDF-12 & 0.42 & 47.25 & 51.95 & 57.17 \\
\hline 13 & MDF-13 & 0.44 & 43.09 & 50.30 & 53.67 \\
\hline 14 & MDF-14 & 0.47 & 40.26 & 45.30 & 51.62 \\
\hline 15 & MDF-15 & 0.49 & 37.15 & 44.52 & 48.08 \\
\hline 16 & MDF-16 & 0.42 & 48.41 & 53.58 & 58.19 \\
\hline 17 & MDF-17 & 0.44 & 44.02 & 51.81 & 54.12 \\
\hline 18 & MDF-18 & 0.46 & 40.73 & 45.95 & 52.10 \\
\hline 19 & MDF-19 & 0.47 & 38.90 & 43.20 & 50.50 \\
\hline 20 & MDF-20 & 0.44 & 43.22 & 49.93 & 53.62 \\
\hline 21 & MDF-21 & 0.47 & 39.85 & 44.61 & 51.42 \\
\hline 22 & MDF-22 & 0.49 & 36.87 & 41.25 & 47.30 \\
\hline 23 & MDF-23 & 0.51 & 35.23 & 40.05 & 46.11 \\
\hline 24 & MDF-24 & 0.42 & 47.94 & 53.05 & 57.82 \\
\hline 25 & MDF-25 & 0.44 & 43.87 & 50.48 & 54.38 \\
\hline 26 & MDF-26 & 0.46 & 40.34 & 45.61 & 52.39 \\
\hline 27 & MDF-27 & 0.48 & 37.65 & 42.28 & 48.55 \\
\hline
\end{tabular}

used the information of mixture proportions of ready-mixed concrete and test results of compressive strength from construction sites. In their study, they have used 1442 compressive strength test results obtained from the specimens having 68 different kinds of mixtures with specified compressive strength of $18 \sim 27 \mathrm{MPa}$, water-cement ratio of $0.39 \sim 0.62$, and maximum aggregate size of $25 \mathrm{~mm}$. In this study, Namyong et al. [19] in situ data has been used for the testing of the suggested model for the prediction of concrete compressive strength.

\section{Results and Discussion}

The objective of the present study was to explore the applicability of the suggested models, that is, model 1 and model 2, for the prediction of concrete compressive strength. This section presents the comparative investigation of results obtained from these approaches and quantitative assessment of the models' predictive abilities. For model 1, the LM algorithm is used for training, whereas tan-sigmoid is used as an activation function for evaluating the prediction accuracy parameters. The results, as presented in Table 7, give the values of $R^{2}$ and RMSE for prediction of concrete compressive strength for both types of mixtures, namely, R1 (dataset with no substitution of cement with FA) and R2 (dataset with substitution of cement with 0.15 FA). From the results in Table 7, it can be observed that, for all the curing days, in both the cases, either R1 or R2, $R^{2}$ is above 0.90 except for $\mathrm{R} 1$ at a curing age of 28 days wherein it is 0.898 . The low values of RMSE for all the mixes at different curing ages also indicate that the model can predict compressive strength of the mixes with high reliability. Also it can be seen that model 1, with LM as the training function, retrieves the result in just a few epochs. The maximum number of epochs taken by the model is just five, which clearly indicates that the time taken for the prediction is also very much less.

In model 2, the addition is chosen as the linking utility. The values of $R^{2}$ and RMSE for prediction of concrete compressive strength for both types of mixtures, namely, R3 (dataset with no substitution of cement with FA) and R4 (dataset with substitution of cement with 0.15 FA), obtainedusing model 2 are provided in Table 7. Prediction 
TABLE 5: Architecture selected for model 1 (ANN model).

\begin{tabular}{|c|c|c|}
\hline Parameters & Values & Description \\
\hline Dataset & $\begin{array}{l}\text { Dataset 1: } 49 \text { (without fly ash) } \\
\text { Dataset 2: } 27 \text { (with fly ash) }\end{array}$ & $\begin{array}{l}\text { Dataset is of two types. One is without any } \\
\text { substitution of cement by fly ash and the second } \\
\text { one is with } 15 \% \text { of the cement replaced by fly ash. } \\
\text { Dataset } 1 \text { is of } 49 \text { tuples in total. Dataset } 2 \text { is of } 27 \\
\text { tuples in total }\end{array}$ \\
\hline $\begin{array}{l}\text { Number of input } \\
\text { parameters }\end{array}$ & $\begin{array}{l}04 \text { (cement (C), water (W), fine aggregate (sand), } \\
\text { coarse aggregate (CA)); in case of } 05 \text { (cement (C), } \\
\text { water (W), fine aggregate (sand), coarse aggregate } \\
(\mathrm{CA}), 28 \text {-day compressive strength (CS28)); in } \\
\text { case of } 06 \text { (cement (C), water (W), fine aggregate } \\
\text { (sand), coarse aggregate (CA), 28-day compressive } \\
\text { strength (CS28), 56-day compressive strength } \\
\text { (CS56)). Fly ash (FA) is used with dataset } 2 \text { only; } \\
\text { all other parameters are the same as dataset } 1\end{array}$ & $\begin{array}{l}\text { When output is } 28 \text { days, then the number of input } \\
\text { parameters is } 04 \text {; when output is } 56 \text { days, the } \\
\text { number of input parameters is } 05 \text { as } 28 \text {-day } \\
\text { compressive strength is taken as input; when } \\
\text { output is } 91 \text { days, the number of input parameters } \\
\text { is } 06 \text { as } 28 \text {-day compressive strength and } 56 \text {-day } \\
\text { compressive strength are also taken as input. In } \\
\text { dataset } 2 \text {, FA is replacing } 15 \% \text { of the cement }\end{array}$ \\
\hline Activation function 1 & $\tan \operatorname{sig}(x)$ & $\tan \operatorname{sig}(x)=\frac{2}{(1+\exp (-2 * x))}-1$ \\
\hline Activation function 2 & $\operatorname{purelin}(x)$ & $\operatorname{purelin}(x)=x$ \\
\hline Performance function & MSE & $\begin{array}{l}\text { MSE }=\frac{\sum_{i=1}^{n}(\text { predictedoutput }- \text { actualoutput })^{2}}{n} \\
\text { where } n \text { is the input patterns }\end{array}$ \\
\hline Net.trainparam.lr & 0.01 & Learning rate \\
\hline Net.trainfcn & trainlm & Levenberg-Marquardt algorithm \\
\hline Net.trainparam.epochs & 10000 & Maximum number of epochs to train \\
\hline Net.trainparam.goal & 0.000001 & Performance goal \\
\hline $\begin{array}{l}\text { Number of hidden layer } \\
\text { neurons }\end{array}$ & 50 & - \\
\hline $\begin{array}{l}\text { Number of output layer } \\
\text { neurons }\end{array}$ & 1 & - \\
\hline
\end{tabular}

equations ((1)-(6)) generated using model 2 are detailed as follows:

$$
\begin{aligned}
& f_{28}=\sqrt{\mathrm{CA}}\left(\left(\left(\left(\left(\left(\left(\frac{(\mathrm{FA}+\mathrm{FA})}{\mathrm{FA}}\right)+\left(\sqrt{(\mathrm{FA})}+\left((\mathrm{FA}+0.640295148)+\frac{(((\mathrm{FA} / 0.661794484)+\sqrt{\mathrm{CA}})))}{\sqrt{\mathrm{FA}}}\right)\right)\right)\right)+\mathrm{CA}\right)+\mathrm{CA}\right)+\mathrm{FA}\right)\right.
\end{aligned}
$$

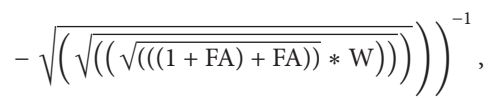

$$
\begin{aligned}
& f_{56}=\left(\left(\left(\frac{\left((\mathrm{W}+(\sqrt{((\mathrm{W}+\mathrm{W}))} * \mathrm{~W})) * f_{28}\right)}{\left(\mathrm{W} *\left(f_{28}+\left(\left(\mathrm{W}+\left(\left(f_{28}+\sqrt{\left(f_{28}\right)}\right)+\mathrm{W}\right)\right)+f_{28}\right)\right)\right)}\right)+(\mathrm{W}+0.488720804)\right) * f_{28}\right) \text {, } \\
& f_{91}=\left(\sqrt{\left(\left(\left(f_{56} * \frac{\sqrt{\left(\sqrt{\left(\left(\left(\left(\left(\left(f_{28} / \mathrm{W}\right)\right) / \mathrm{W}\right) / \mathrm{W}\right)+\left(\left(\sqrt{(\mathrm{W} *(\mathrm{CA}-\mathrm{FA}))}+f_{28}\right)\right)\right)\right.}+f_{28}\right)}}{\mathrm{W}}\right)\right) *\left(\left(\mathrm{~W}+\left(\frac{f_{28}}{\mathrm{~W}}\right)\right) *\left((\mathrm{~W} * \mathrm{~W})+\left(\frac{f_{28}}{\mathrm{~W}}\right)\right)\right)\right)}\right) \\
& f_{28}^{\prime}=\left(\sqrt{\mathrm{CA}}(\mathrm{W}+((((\mathrm{FA} * \sqrt{((((\mathrm{FA}+\mathrm{CA})+\mathrm{FA})+\mathrm{FA}) * \mathrm{FA}))})+((\mathrm{FA}+(\sqrt{\mathrm{CA}}+((\mathrm{W}+\mathrm{CA})+\mathrm{W})))+\mathrm{CA}))+(\sqrt{\mathrm{FA}}+\mathrm{FA}))+(\mathrm{W}+\mathrm{FA})))^{-1}\right) \text {, } \\
& f_{56}^{\prime}=\left(\sqrt{\left(\frac{\left(\left(\left(-6.43 e-002+f_{28}^{\prime}\right)+\sqrt{(\sqrt{((\sqrt{(\sqrt{\mathrm{CA}})}) * \mathrm{CA})}))}\right)\right.}{\sqrt{\left(\sqrt{\left(\left(\sqrt{\mathrm{CA}} *\left(\left(\sqrt{\left(\left(\sqrt{\left(\left(\left(\mathrm{W} / f_{28}^{\prime}\right) *\left(f_{28}^{\prime} \pm 6.78 e-002\right)\right)\right.}+\sqrt{\mathrm{FA}}\right)\right)} / \sqrt{(\sqrt{(\sqrt{\mathrm{CA}})})}+f_{28}^{\prime}\right)\right)\right.\right.}\right)}}\right)}\right) * f_{28}^{\prime}, \\
& f_{91}^{\prime}=\left(\sqrt{((((\mathrm{W} * 0.577551961) * \sqrt{((\sqrt{(((\mathrm{W} * 0.572648823)))}))})))} *\left(f_{28}^{\prime} * 3.1462729\right)\right),
\end{aligned}
$$


TABLE 6: Architecture selected for model 2 (GP model).

\begin{tabular}{|c|c|c|}
\hline Parameters & Values & Description \\
\hline Initial population size & $\begin{array}{l}\text { Dataset 1: } 49 \text { (without fly ash) } \\
\text { Dataset 2: } 27 \text { (with fly ash) }\end{array}$ & $\begin{array}{l}\text { Dataset is of two types. One is without any } \\
\text { substitution of cement by fly ash and the } \\
\text { second one is with } 0.15 \text { of the cement replaced } \\
\text { by fly ash. Dataset } 1 \text { is of } 49 \text { tuples in total. } \\
\text { Dataset } 2 \text { is of } 27 \text { tuples in total }\end{array}$ \\
\hline $\begin{array}{l}\text { Number of input } \\
\text { parameters }\end{array}$ & $\begin{array}{l}04 \text { (cement (C), water (W), fine aggregate } \\
\text { (sand), coarse aggregate (CA)). } 05 \text { (cement (C), } \\
\text { water (W), fine aggregate (sand), coarse } \\
\text { aggregate (CA), 28-day compressive strength } \\
(\mathrm{CS} 28)), 06 \text { (cement (C), water (W), fine } \\
\text { aggregate (sand), coarse aggregate (CA), } \\
\text { 28-day compressive strength (CS28), 56-day } \\
\text { compressive strength (CS56)). Fly ash (FA) is } \\
\text { used with dataset } 2 \text { only; all other parameters } \\
\text { are the same as dataset } 1\end{array}$ & $\begin{array}{l}\text { When output is } 28 \text { days, then the number of } \\
\text { input parameters is } 04 \text {; when output is } 56 \text { days, } \\
\text { the number of input parameters is } 05 \text { as } 28 \text {-day } \\
\text { compressive strength is taken as input; when } \\
\text { output is } 91 \text { days, the number of input } \\
\text { parameters is } 06 \text { as } 28 \text {-day compressive } \\
\text { strength and } 56 \text {-day compressive strength are } \\
\text { also taken as input. In dataset } 2 \text {, FA is replacing } \\
15 \% \text { of the cement }\end{array}$ \\
\hline Function set & $+,-, *, /$, sqrt & Set of functions used \\
\hline Training percentage & 75 & - \\
\hline Selection method & Tournament & - \\
\hline $\begin{array}{l}\text { Tournament size of } \\
\text { replacement }\end{array}$ & 3 & - \\
\hline Maximum generations & 100000 & Maximum number of iterations \\
\hline Crossover & 0.7 & Probability of crossover \\
\hline Mutation & $5 . e-002$ & Probability of mutation \\
\hline $\mathrm{Mu}$ & 100 & Population size \\
\hline Lamda & 150 & Number of children produced \\
\hline Objectives & COD, RMSE & $\begin{array}{l}\text { Coefficient of determination, root mean square } \\
\text { error }\end{array}$ \\
\hline
\end{tabular}

TABLE 7: Results of model 1 (ANN) and model 2 (GP).

\begin{tabular}{|c|c|c|c|c|}
\hline \multirow{2}{*}{\multicolumn{2}{|c|}{$\begin{array}{c}\text { Model 1: } \\
\text { Artificial Neural Network (ANN) }\end{array}$}} & \multicolumn{3}{|c|}{ Training of the dataset } \\
\hline & & \multirow{2}{*}{ Epochs taken } & \multirow{2}{*}{ Coefficient of determination $\left(R^{2}\right)$} & \multirow{2}{*}{ Root mean square error (RMSE) } \\
\hline Result number & Curing time & & & \\
\hline \multirow{3}{*}{ R1 (without fly ash) } & 28 days & 04 & 0.898 & $6.9762 e-006$ \\
\hline & 56 days & 05 & 0.998 & $1.2712 e-007$ \\
\hline & 91 days & 03 & 01 & $7.3640 e-009$ \\
\hline \multirow{3}{*}{ R2 (with 0.15 fly ash) } & 28 days & 05 & 0.996 & $3.8809 e-007$ \\
\hline & 56 days & 04 & 01 & $3.6873 e-009$ \\
\hline & 91 days & 04 & 01 & $2.2181 e-010$ \\
\hline \multicolumn{5}{|c|}{ Model 2: Genetic Programming (GP) } \\
\hline \multirow{4}{*}{ R3 (without fly ash) } & 28 days & \multirow{6}{*}{ Not applicable } & 0.77438 & 0.01067 \\
\hline & 56 days & & 0.99999 & 0.00550 \\
\hline & 91 days & & 0.99999 & 0.00644 \\
\hline & 28 days & & 0.93781 & 0.01415 \\
\hline \multirow[t]{2}{*}{ R4 (with 0.15 fly ash) } & 56 days & & 0.94483 & 0.00910 \\
\hline & 91 days & & 0.96681 & 0.00689 \\
\hline
\end{tabular}

where $f_{28}, f_{56}$, and $f_{91}$ are the concrete compressive strengths at curing ages of 28,56 , and 91 days, respectively, when no substitution has been done. $f_{28}^{\prime}, f_{56}^{\prime}$, and $f_{91}^{\prime}$ are the concrete compressive strengths at curing ages of 28,56 , and 91 days, respectively, when $0.15 \mathrm{FA}$ is used as substitution of cement.
$\mathrm{W}$ is the $\mathrm{W} / \mathrm{CM}$ ratio, $\mathrm{FA}$ is the $\mathrm{FA} / \mathrm{CM}$, and $\mathrm{CA}$ is the CA/CM.

From the results, tabulated in Table 7 , it can be observed that for R3 mixtures, at curing ages of 56 and 91 days, the values of $R^{2}$ are of the order of 0.90 and 0.87 , respectively, 


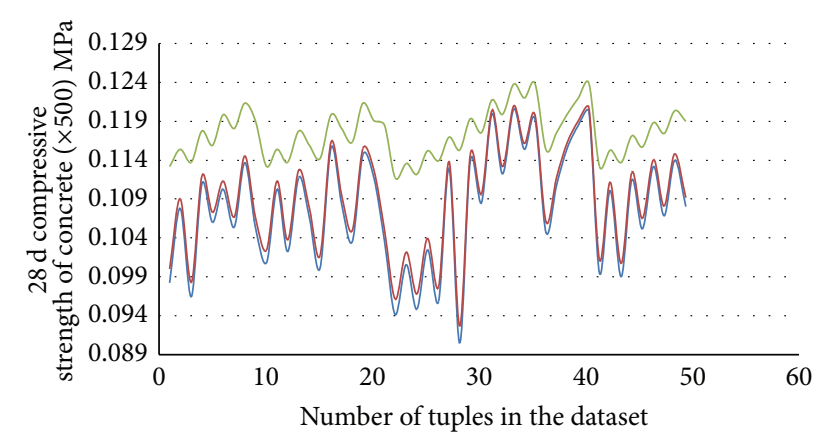

Exp. $28 \mathrm{~d} \mathrm{CS}$
Pre. ANN $28 \mathrm{~d}$ CS

FIGURE 1: Comparison between actual and predicted values of $28 \mathrm{~d}$ compressive strength of concrete.

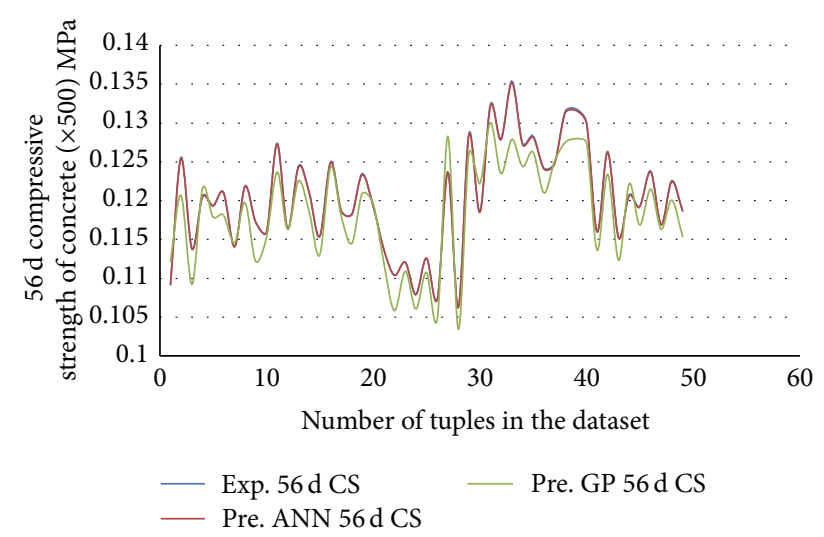

FIGURE 2: Comparison between actual and predicted values of $56 \mathrm{~d}$ compressive strength of concrete.

with an RMSE value of 0.0029 in case of 56 days and 0.05 in case of 91 days, indicating a reasonably good fit of the model. However, in case of 28-day curing, $R^{2}$ obtained is 0.77 , which is approximately 0.30 less than the suggested good model fit $\left(R^{2}\right.$ more than or equal to 0.80 ). In case of prediction of compressive strength for $\mathrm{R} 4$ mixtures, with $0.15 \mathrm{FA}, R^{2}$ obtained is above or equal to 0.92 for all the cases with the highest value of 0.97 with an RMSE value of 0.009 at curing age of 91 days. This indicates that model 2 provides the best prediction at 91-day curing for mixes with FA. Figures 1-6 provide comparison of the predicted results obtained using model 1 , model 2 , and experimental laboratory results.

It can be clearly observed from these figures that model 1 predicts compressive strength values very near to the experimentally obtained values as compared to model 2 results. To further test the efficacy and reliability of the models, the in situ compressive strength data at curing age of 28 days (as provided in Namyong et al. [19]) has been used in the study. Figure 7 shows the results of the testing of models for the in situ dataset of compressive strength. It has been clearly observed that model 1 is more reliable and provides more accurate prediction for the in situ dataset as well.

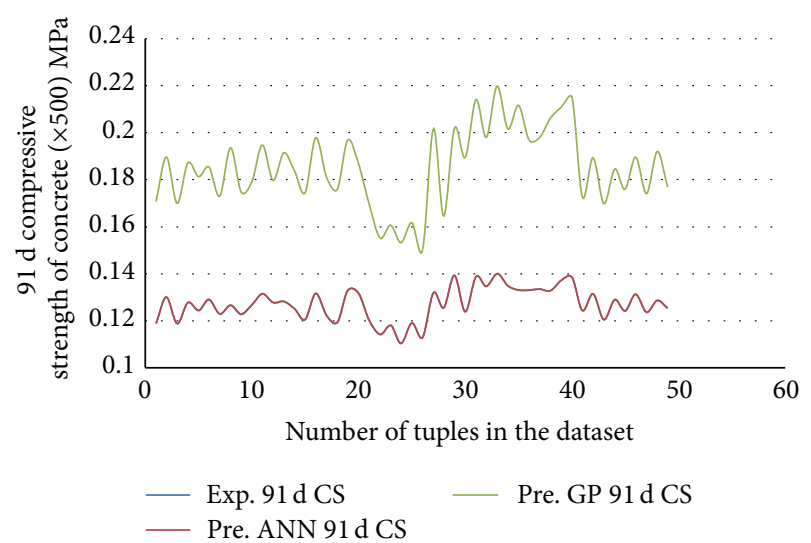

FIGURE 3: Comparison between actual and predicted values of $91 \mathrm{~d}$ compressive strength of concrete.

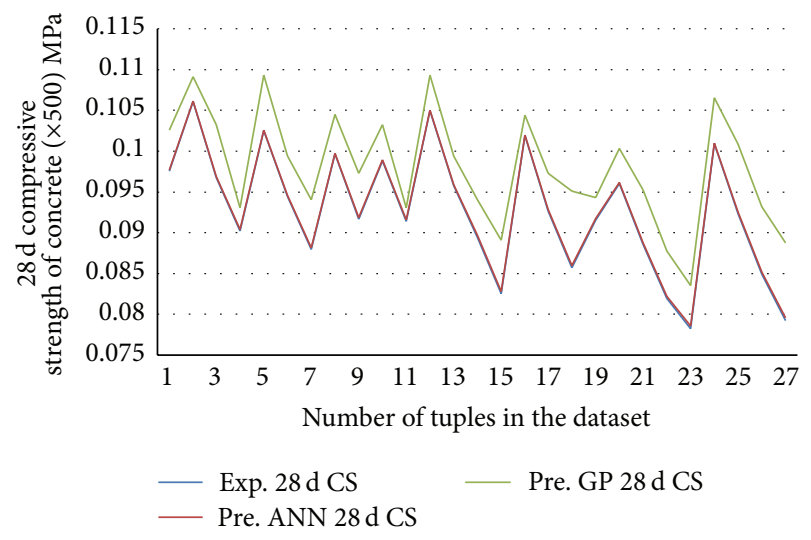

FIGURE 4: Comparison between actual and predicted values of $28 \mathrm{~d}$ compressive strength of concrete with FA.

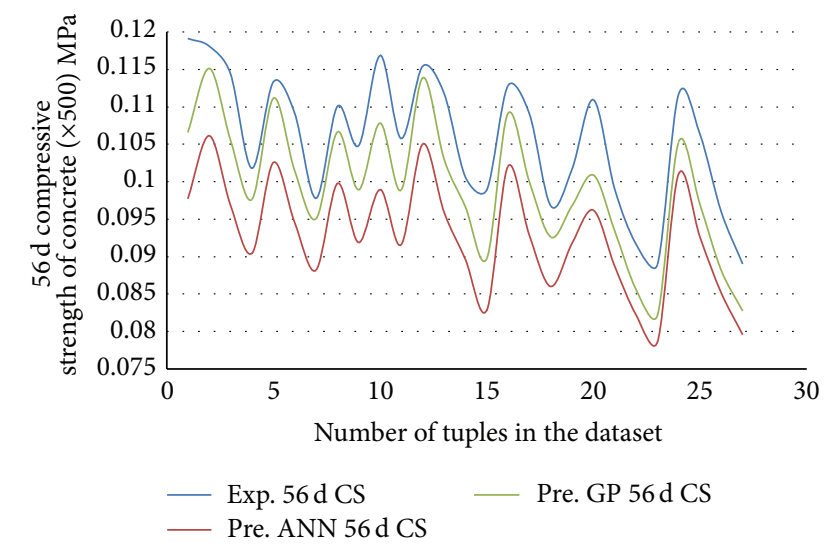

FIGURE 5: Comparison between actual and predicted values of $56 \mathrm{~d}$ compressive strength of concrete with FA.

\section{Conclusions}

On the comparative analysis of GP and ANN techniques, used for the prediction of concrete compressive strength without and with FA, it can be concluded that ANN model is the most reliable technique for the purpose. The RMSE 


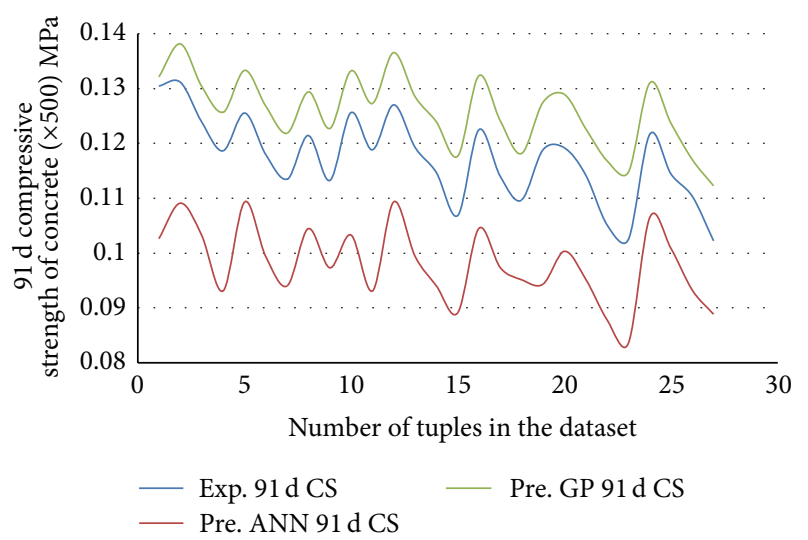

FIGURE 6: Comparison between actual and predicted values of $91 \mathrm{~d}$ compressive strength of concrete with FA.

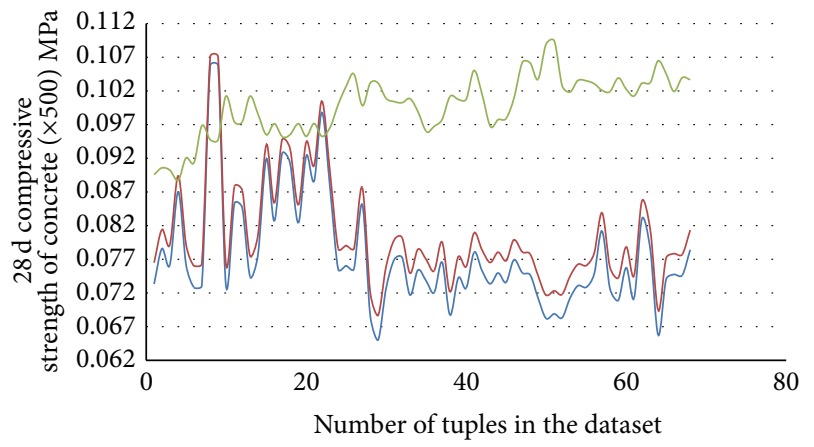

$\begin{array}{ll}\text { Exp. } 28 \mathrm{~d} \text { CS } & \text { Pre. GP } 28 \mathrm{~d} \text { CS }\end{array}$

FIGURE 7: Validation of the proposed model of $28 \mathrm{~d}$ compressive strength of concrete with in situ dataset as per [19].

values, so obtained, are small enough to indicate that the estimates are most precise and the trained networks supply superior results. According to statistics, if a proposed model gives $R^{2}>0.8$, there is a well-built correlation between predicted and measured values for the data available in the dataset. As has been observed, for both the models, $R^{2}$ is greater than 0.8 for all cases, except R3 mixture (in Table 7) strength at 28 days, which proves that either of the models can be used for prediction purposes. However, the prediction model using model 1, that is, ANN model, confirms a high degree of steadiness with experimentally evaluated concrete compressive strength specimens used. As an outcome, ANN may serve as a strong predictive tool, for prediction of both experimental and in situ data and it may provide perfect and valuable explicit formulation for many civil engineering applications, wherein predictive pronouncements are required.

\section{Conflict of Interests}

The authors declare that there is no conflict of interests regarding the publication of this paper.

\section{References}

[1] H.-G. Ni and J.-Z. Wang, "Prediction of compressive strength of concrete by neural networks," Cement and Concrete Research, vol. 30, no. 8, pp. 1245-1250, 2000.

[2] A. Baykasoglu, T. Dereli, and S. Taniş, "Prediction of cement strength using soft computing techniques," Cement and Concrete Research, vol. 34, no. 11, pp. 2083-2090, 2004.

[3] S. Akkurt, G. Tayfur, and S. Can, "Fuzzy logic model for the prediction of cement compressive strength," Cement and Concrete Research, vol. 34, no. 8, pp. 1429-1433, 2004.

[4] A. Öztaş, M. Pala, E. Özbay, E. Kanca, N. Çağlar, and M. A. Bhatti, "Predicting the compressive strength and slump of high strength concrete using neural network," Construction and Building Materials, vol. 20, no. 9, pp. 769-775, 2006.

[5] M. Pala, E. Özbay, A. Öztaş, and M. I. Yuce, "Appraisal of longterm effects of fly ash and silica fume on compressive strength of concrete by neural networks," Construction and Building Materials, vol. 21, no. 2, pp. 384-394, 2007.

[6] N. P. Rajamane, J. A. Peter, and P. S. Ambily, "Prediction of compressive strength of concrete with fly ash as sand replacement material," Cement and Concrete Composites, vol. 29, no. 3, pp. 218-223, 2007.

[7] M. Ozturan, B. Kutlu, and T. Ozturan, "Comparison of concrete strength prediction techniques with artificial neural network approach," Building Research Journal, vol. 56, pp. 23-36, 2008.

[8] M. M. Alshihri, A. M. Azmy, and M. S. El-Bisy, "Neural networks for predicting compressive strength of structural light weight concrete," Construction and Building Materials, vol. 23, no. 6, pp. 2214-2219, 2009.

[9] M. Saridemir, "Prediction of compressive strength of concretes containing metakaolin and silica fume by artificial neural networks," Advances in Engineering Software, vol. 40, no. 5, pp. 350-355, 2009.

[10] M. Saridemir, "Genetic programming approach for prediction of compressive strength of concretes containing rice husk ash," Construction and Building Materials, vol. 24, no. 10, pp. 19111919, 2010.

[11] A. M. Diab, H. E. Elyamany, A. E. M. Abd Elmoaty, and A. H. Shalan, "Prediction of concrete compressive strength due to long term sulfate attack using neural network," Alexandria Engineering Journal, vol. 53, no. 3, pp. 627-642, 2014.

[12] M. Kumar, Reliability based design of structural elements [Ph.D. thesis], Thapar Institute of Engineering and Technology Patiala, Patiala, India, 2002.

[13] P. K. Simpson, Ed., Neural Networks, Theory, Technology, and Applications, IEEE, New York, NY, USA, 1996.

[14] K. Knight, "Connectionist ideas and algorithms," Communications of the ACM, vol. 33, no. 11, pp. 58-74, 1990.

[15] A. K. Sharma, R. K. Sharma, and H. S. Kasana, "Prediction of first lactation 305-day milk yield in Karan Fries dairy cattle using ANN modeling," Applied Soft Computing Journal, vol. 7, no. black3, pp. 1112-1120, 2007.

[16] A. Kamalloo, Y. Ganjkhanlou, S. H. Aboutalebi, and H. Nouranian, "Modeling of compressive strength of Metakaolin based geopolymers by the use of artificial neural network," International Journal of Engineering, vol. 23, no. 2, pp. 145-152, 2010.

[17] J. R. Koza, Genetic Programming: On the Programming of Computers by Means of Natural Selection, The MIT Press, Cambridge, Mass, USA, 1992. 
[18] A. Ghodratnamaa, R. Tavakkoli-Moghaddam, and A. Babolic, "Comparing three proposed meta-heuristics to solve a new P-HUB location-allocation problem," International Journal of Engineering, vol. 26, no. 9, pp. 1043-1058, 2013.

[19] J. Namyong, Y. Sangchun, and C. Hongbum, "Prediction of compressive strength of In-situ concrete based on mixture proportions," Journal of Asian Architecture and Building Engineering, vol. 3, no. 1, pp. 9-16, 2004. 

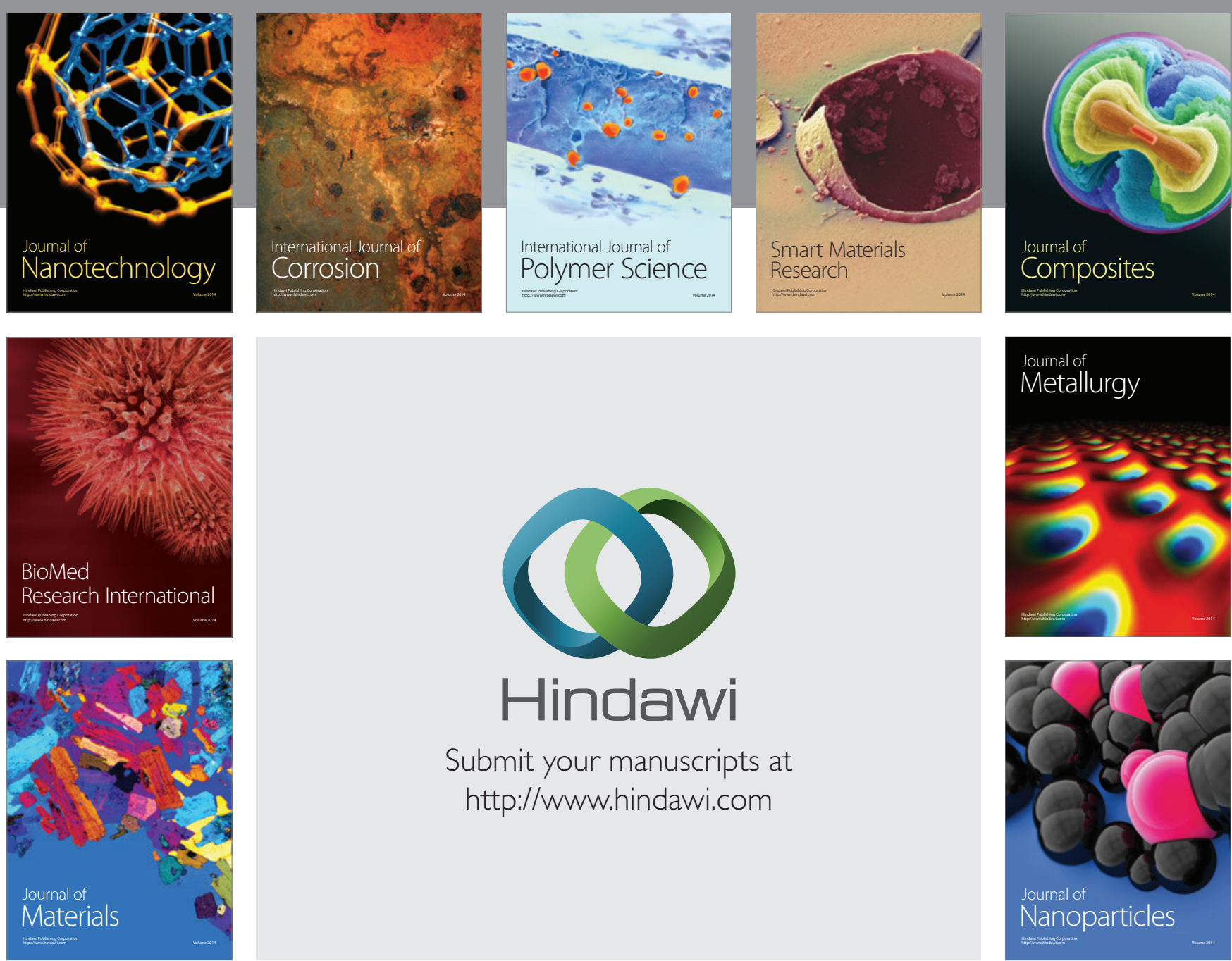

\section{Hindawi}

Submit your manuscripts at

http://www.hindawi.com

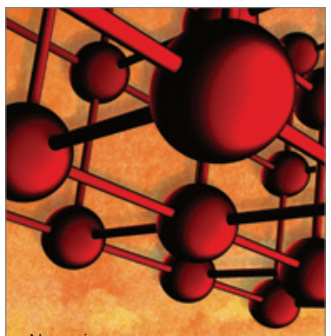

Materials Science and Engineering
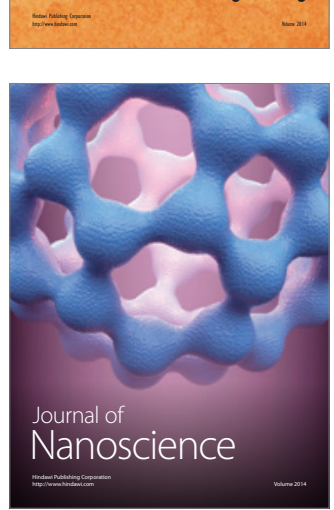
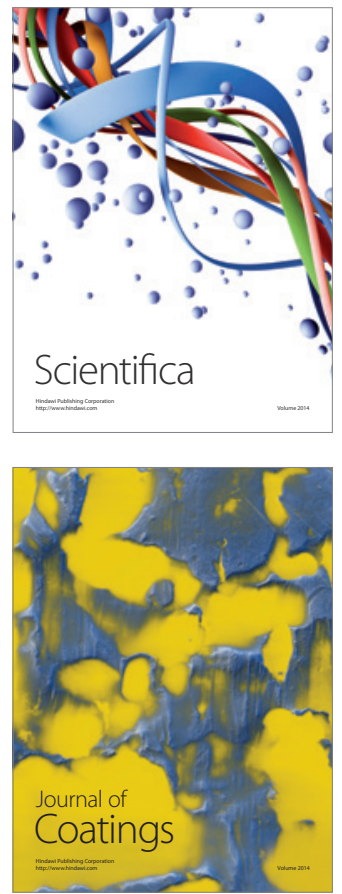
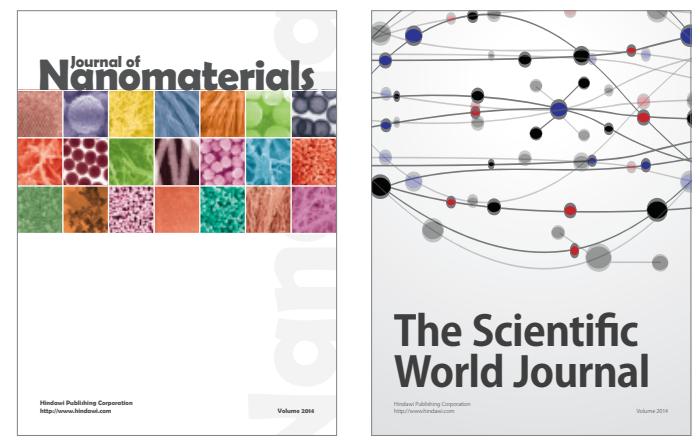

The Scientific World Journal
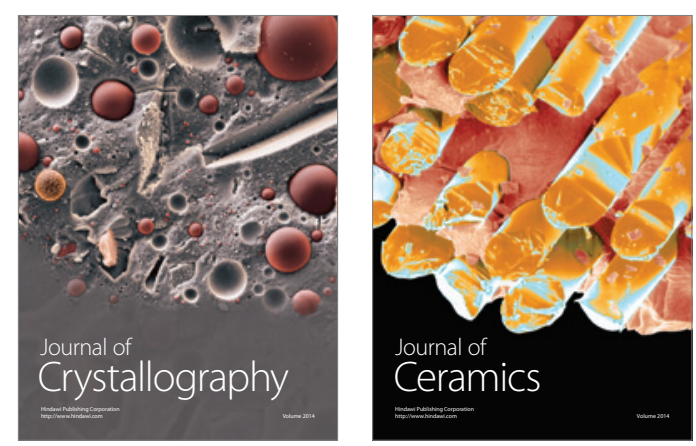
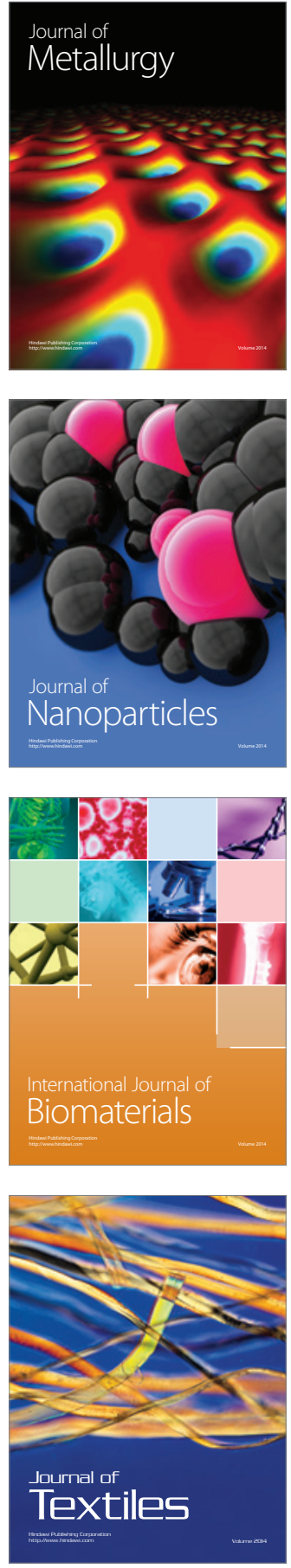